\title{
Outcome of Adenoid Cystic Carcinoma of Head and Neck After Postoperative Intensity Modulation Radiotherapy: A Single Institution Study
}

This article was published in the following Dove Press journal:

Cancer Management and Research

\author{
Peng $X u^{\prime}$ \\ Shuo Wang' \\ Yukun Luo' \\ Jun Yin' \\ Yazid Belkacemi ${ }^{2}$ \\ Shun Lu' \\ Mei Feng' \\ Jinyi Lang (D)
}

'Department of Radiation Oncology, Sichuan Cancer Hospital and Research Institute, Chengdu, People's Republic of China; ${ }^{2}$ Department of Radiation

Oncology, APHP - University Hospital of Henri Mondor, Creteil, France
Correspondence: Jinyi Lang Department of Radiation Oncology, Sichuan Cancer Hospital and Research Institute, Chengdu, 61004I, People's

Republic of China

$\mathrm{Tel}+862885420152$

Email langjy610@I63.com
Objective: This study was retrospectively evaluated the outcome of postoperative intensity modulation radiotherapy (IMRT) for patients with adenoid cystic carcinoma of head and neck (ACCHN), and identified the unfavorable prognostic factors.

Methods: Fifty-five ACCHN patients treated in Sichuan Cancer Hospital between January 2007 and December 2016 were retrospectively evaluated. Median age of patient was 47 years (range, 21-73 years). Thirty-five patients were male and 20 were female. In 30 patients, tumors were located in major salivary glands $(54.5 \%)$, and 25 patients in minor salivary glands $(45.5 \%)$. The numbers of R0, R1, and R2 surgical resection classification patients were $22(40.0 \%), 20(36.4 \%)$, and 13 (23.6\%). The median total RT dose was $62 \mathrm{~Gy}$ (range, 46-72 Gy), and $54.5 \%$ of patients were treated with adjuvant chemotherapy. Statistical analyses were performed using the Log rank test for univariate analysis and the Cox proportional hazard model for multivariate analysis.

Results: Median follow-up period was 68.5 months (12-132 months). The 5-year local-regional recurrence-free survival (LRRFS), distant metastasis-free survival (DMFS) and overall survival (OS) were $93.9 \%, 75.3 \%$ and $82.5 \%$. In univariate analysis, T stages $(p=0.025)$ and AJCC stages $(p=0.036)$ were the prognostic factors for OS; Age $(p=0.042)$, T stages $(p=0.025), \mathrm{N}$ stages $(p=0.021)$, AJCC stages $(p=0.021)$ and adjuvant chemotherapy $(p=0.010)$ were the prognostic factors for DMFS; T stage $(p=0.049)$ was the prognostic factor for LRRFS. In multivariate factors analyses, T stages $(p=0.026)$, AJCC stages $(p=0.028)$ and RT dose $(p=0.025)$ were the significant prognosticators for OS. The most common acute toxicities over three degrees were myelosuppression (5.5\%), mucositis (9.1\%) and dermatitis (1.8\%).

Conclusion: Postoperative IMRT seems to achieve reasonable local-regional control and OS in patients with adenoid cystic carcinoma of head and neck, with acceptable treatment relative toxicities.

Keywords: ACCHN, postoperative radiotherapy, IMRT, clinical efficacy, prognostic analysis

\section{Introduction}

Adenoid cystic carcinoma (ACC) is an uncommon tumor of the head and neck, accounting for about $1 \%$ of head and neck malignancies and $10 \%$ of malignant tumors of the salivary glands. The most common location of ACC often occurs in large salivary glands (parotid glands, submandibular glands, sublingual glands) and 
small salivary glands (palate, nasal cavity, sinuses, tongues, tear glands, trachea, etc). ${ }^{1}$ In addition, head and neck adenoid cystic carcinoma (ACCHN) is often has a high recurrence rate and occurs as advanced tendency for distant metastasis, often in the form of lung, liver, and bone. ${ }^{2,3}$ ACCHN occurred in all age groups, with higher incidence in middle-aged and older patients, women slightly more likely than men. ${ }^{4}$ The standard treatment method is surgical excision, and then according to the surgical margin and histopathological results, postoperative adjuvant radiotherapy is recommended. ${ }^{1}$ However, due to the neural invasion characteristic of ACCHN, it is difficult to obtain negative surgical margins even if complete resection can be evaluated by preoperative imaging.

Because of the low incidence of ACCHN, survival has been rarely reported. Most postoperative radiotherapy is conformal radiotherapy. ${ }^{5,6}$ This study reported the outcome and toxicity for ACCHN patients treated by surgery combined with intensity modulated conformal radiotherapy (IMRT) in a single institute.

\section{Materials and Methods}

\section{Ethics Statement}

All procedures performed involving human participants were in accordance with the ethical standards of the institutional and/or national research committee and with the 1964 Helsinki declaration and its later amendments or comparable ethical standards. The study was approved by the ethical committees of Sichuan Cancer Hospital \& Institute, Chengdu, China. All patients provided informed consent.

All investigated patients presented between from January 2007 to December 2016, with pathologically confirmed ACC and no distant metastasis. Among them, five patients were lost to follow-up, two cases have not completed the postoperative radiotherapy, and 10 cases were treated by conformal radiotherapy, a total of 55 patients were included in the retrospective analysis. The clinical characteristics and treatments of patients are shown in Table 1.

All the patients underwent surgery and postoperative adjuvant IMRT. Postoperative pathological analysis showed that the total resection was R0, the microscopic residual was R1 and the macroscopic residual was $\mathrm{R} 2$. Postoperative residual area (GTV) and neck lymph node metastasis (GTV-N) were sketched according to the residual area and positive metastatic lymph node shown by
Table I Patient Characteristics

\begin{tabular}{|l|l|c|}
\hline \multicolumn{2}{|l|}{ Characteristics } & Total Patients (\%) \\
\hline Gender & Male & $35(63.6)$ \\
& Female & $20(36.4)$ \\
\hline Age, years & $\leq 47$ & $28(50.9)$ \\
& $>47$ & $27(49.1)$ \\
\hline Primary site & Large salivary gland & $30(54.5)$ \\
& Small salivary gland & $25(45.5)$ \\
\hline T stages & I-2 & $24(43.6)$ \\
& $3-4$ & 3 I (56.4) \\
\hline N stages & 0 & 5 I (92.7) \\
& I-2 & $4(7.3)$ \\
\hline AJCC stages & I-II & $23(41.8)$ \\
& III-IVB & $32(58.2)$ \\
\hline Surgical resection level & R0 & $22(40.0)$ \\
& RI & $20(36.4)$ \\
& R2 & $26(23.6)$ \\
\hline Chemotherapy & No & $29(52.7)$ \\
\hline Yes & $18(32.7)$ \\
& $<60 G y$ & \\
\hline
\end{tabular}

CT, MRI or PET/CT. CTV1 was the postoperative tumor bed area, and CTV2 was the lymph drainage area. Prescription doses for each planned target area were GTV/GTV-N 65.0-73.0Gy (median 66Gy). Patients with R0\&R1 margins were treated with CTV1 50-66Gy (median 54Gy) and CTV2 46-55Gy (median 48Gy). Twenty-nine $(54.5 \%)$ patients received postoperative adjuvant chemotherapy; chemotherapy drugs were based on cisplatin, and the median cycle of chemotherapy was three.

Acute reactions and late complications were evaluated according to the Common Terminology Criteria for Adverse Events version 4.0. ${ }^{7}$ The patients were followed up every three months for one year after radiotherapy, every six months for 2-3 years, and annually after three years. Regular followup studies included physical examination, blood tests, chest $\mathrm{X}$-ray/CT, abdominal ultrasound, head and neck MRI.

Statistical analyses were performed with SPSS Statistics 22 (IBM, Armonk, NY, USA). Overall survival (OS), distant disease-free survival (DMFS) and localregional recurrence-free survival (LRRFS) curves were estimated with the Kaplan-Meier method and were compared with the Log rank test. Multivariate analysis was 


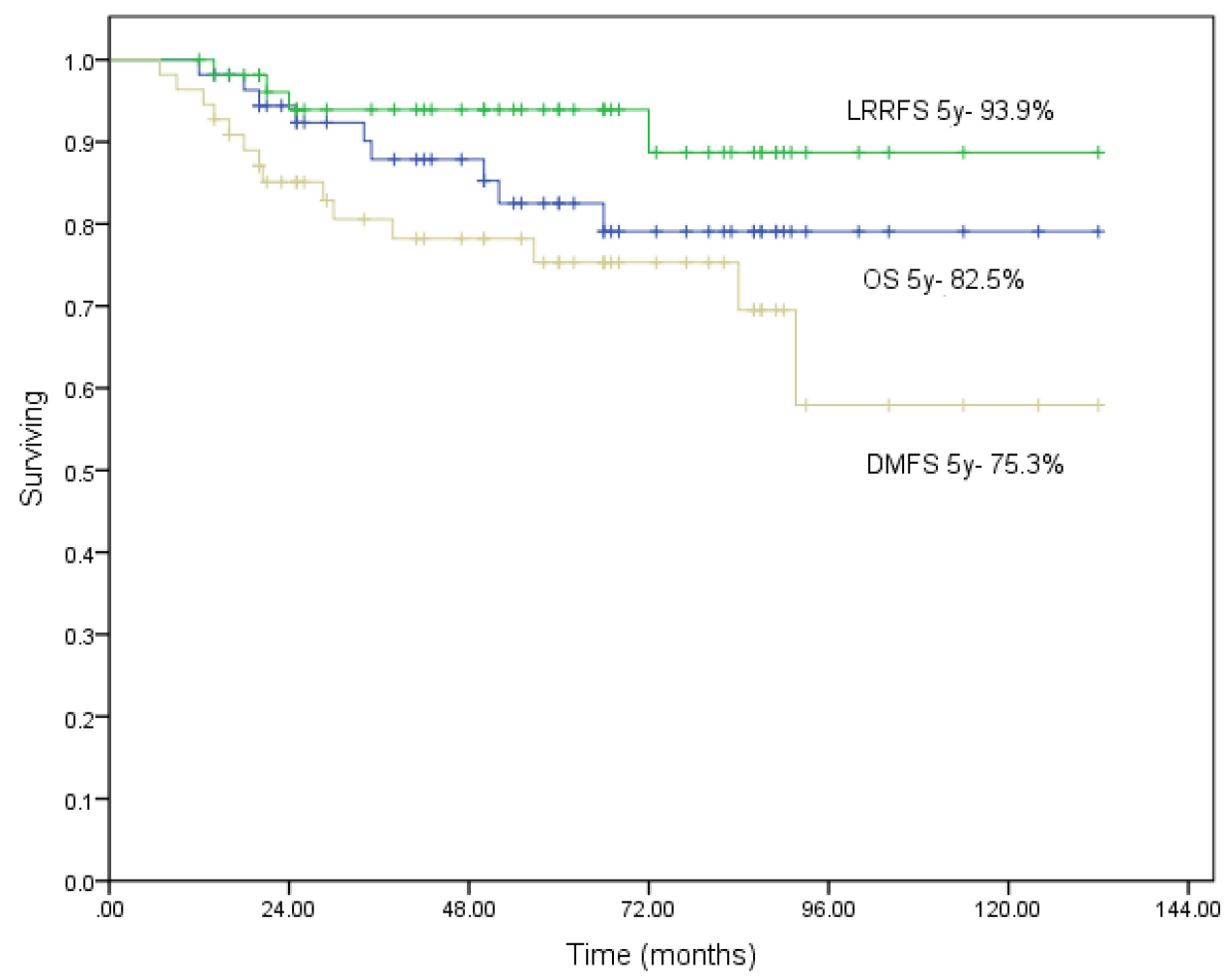

Figure I Overall survival (OS), distant disease-free survival (DMFS), local-regional recurrence-free survival (LRRFS) for all patients (Kaplan-Meier method).

performed with the Cox proportional-hazards model. All $p$ values are two-sided and $p$ values of less than 0.05 were considered to be statistically significant.

\section{Results}

Median age of the patients was 47 years (range, 21-74 years), of whom 35 were male and 20 females (1.75:1). AJCC stage (7th edition) I, II, III, IV patients were 3 (5.5\%), $20(36.4 \%), 12(21.8 \%)$ and 20 cases $(36.4 \%)$, respectively. In 15 cases $(27.3 \%)$ tumor arose in the parotid glands, 7 cases (12.7\%) in the submandibular glands and 8 cases $(14.5 \%)$ in sublingual glands. Pathological margins were R0 in $22(40.0 \%)$ patients, R1 in 20 (36.4\%) patients and R2 in $13(23.6 \%)$ patients. Median follow-up time for the whole group was 68.5 months (range, 12-132 months). Local regional recurrence (LRR) occurred in four cases $(7.3 \%)$, distant metastasis (DM) occurred in 14 cases (25.5\%), and nine (16.4\%) patients death. Main sites of distant metastasis were the lungs (78.6\%), bones (28.6\%), liver $(21.4 \%)$, and brain (7.1\%). Median survival time for the whole group was 58.6 months. The 5-year LRRFS, DMFS and OS were 93.9\%, 75.3\% and 82.5\%, respectively (Figure 1). Table 2 lists the results of Log rank tests for the candidate prognostic factors. In the univariate analysis, the following parameters were associated with overall survival rate: T stages $(p=0.025)$, and AJCC stages $(p=0.036)$. Additionally, $\mathrm{T}$ stages is also significant associated with DMFS $(p=0.049)$. However, gender, surgical resection level, postoperative radiotherapy dose and other factors did not show significant association with clinical outcome. The significant effects of $\mathrm{T}$ stages (T1/2 and T3/4) on the OS, LRRFS and DFMS are seen in Figure 2.

In multivariate analysis, T stages $(p=0.026)$ and AJCC stages $(p=0.028)$ remained statistically significant association with OS after adjustment (Table 3 ). Factors of independent importance on the DFMS were $\mathrm{N}$ stages $(p=0.017)$ and AJCC stages $(p=0.040)$.

As shown in Table 4, acute adverse reactions of grade 3 or above mainly included myelosuppression (3 cases, $5.5 \%$ ), mucositis (5 cases, 9.1\%), and dermatitis (1 case, $1.8 \%$ ). Chronic adverse reactions mainly included grade 1-3 trismus, xerostomia, hearing loss, etc. No acute and chronic adverse reactions of grade 4 or higher occurred.

\section{Discussion}

The recommended treatment for ACCHN is radical surgical resection, combine with postoperative radiotherapy. ${ }^{8}$ 
Table 2 Univariate Analysis for Overall Survival (OS), Distant Disease-Free Survival (DMFS) and Local-Regional Recurrence-Free Survival (LRRFS)

\begin{tabular}{|c|c|c|c|c|c|c|c|}
\hline & & OS (\%) & $\mathbf{P}$ & DMFS (\%) & $\mathbf{P}$ & LRRFS (\%) & $\mathbf{P}$ \\
\hline \multirow[t]{2}{*}{ Gender } & Male & 79.9 & \multirow[t]{2}{*}{0.301} & 73.8 & \multirow[t]{2}{*}{0.479} & 96.6 & \multirow[t]{2}{*}{0.629} \\
\hline & Female & 87.7 & & 78.2 & & 89.4 & \\
\hline \multirow[t]{2}{*}{ Age, years } & $\leq 47$ & 82.3 & \multirow[t]{2}{*}{0.923} & 61.3 & \multirow[t]{2}{*}{0.042} & 91.7 & \multirow[t]{2}{*}{0.869} \\
\hline & $>47$ & 83.0 & & 88.4 & & 96.0 & \\
\hline \multirow[t]{2}{*}{ Primary site } & Large salivary gland & 88.6 & \multirow[t]{2}{*}{0.229} & 75.9 & \multirow[t]{2}{*}{0.958} & 92.8 & \multirow[t]{2}{*}{0.833} \\
\hline & Small salivary gland & 75.6 & & 74.3 & & 95.5 & \\
\hline \multirow[t]{2}{*}{ T stages } & $\mathrm{I}-2$ & 94.1 & \multirow[t]{2}{*}{0.025} & 91.5 & \multirow[t]{2}{*}{0.041} & 100 & \multirow[t]{2}{*}{0.04} \\
\hline & $3-4$ & 73.2 & & 62.3 & & 89.2 & \\
\hline \multirow[t]{2}{*}{$\mathrm{N}$ stages } & 0 & 82.9 & \multirow[t]{2}{*}{0.698} & 77.1 & \multirow[t]{2}{*}{0.021} & 93.5 & \multirow[t]{2}{*}{0.598} \\
\hline & $\mathrm{I}-2$ & 75.0 & & 50.0 & & 100.0 & \\
\hline \multirow[t]{2}{*}{ AJCC stages } & I-II & 93.8 & \multirow[t]{2}{*}{0.036} & 91.1 & \multirow[t]{2}{*}{0.021} & 100 & \multirow[t]{2}{*}{0.065} \\
\hline & III-IVB & 74.2 & & 63.8 & & 89.6 & \\
\hline \multirow[t]{2}{*}{ Surgical resection level } & Ro & 93.3 & \multirow[t]{2}{*}{0.093} & 83.6 & \multirow[t]{2}{*}{0.629} & 89.7 & \multirow[t]{2}{*}{0.621} \\
\hline & $R \mid \& R 2$ & 76.7 & & 70.5 & & 96.4 & \\
\hline \multirow[t]{2}{*}{ Chemotherapy } & Yes & 90.9 & \multirow[t]{2}{*}{0.073} & 91.6 & \multirow[t]{2}{*}{0.010} & 88.3 & \multirow[t]{2}{*}{0.384} \\
\hline & No & 74.1 & & 59.9 & & 100 & \\
\hline \multirow[t]{2}{*}{ Radiotherapy dose } & $<60 \mathrm{~Gy}$ & 75.6 & \multirow[t]{2}{*}{0.509} & 69.2 & \multirow[t]{2}{*}{0.890} & 94.4 & \multirow[t]{2}{*}{0.734} \\
\hline & $\geq 60 \mathrm{~Gy}$ & 86.6 & & 78.7 & & 93.6 & \\
\hline
\end{tabular}

To date, few studies have reported the clinical outcome and toxicities for ACCHN patients treated by IMRT. In this study, we retrospectively analyzed the outcome of postoperative IMRT for 55 patients with ACCHN, and identified the unfavorable prognostic factors.

Takebayashi et $\mathrm{al}^{9}$ have reported the 5-year LRRFS, DMFS and OS were $79.3 \%, 62.6 \%$ and $82.2 \%$ in 130 patients with ACCHN treated by surgery and radiotherapy. The SEER database ${ }^{4}$ showed locally advanced ACCHN 5-year OS was 78.9-93.9\%. The 5-year LRRFS, DMFS and OS in this study were $93.9 \%, 75.3 \%$ and $82.5 \%$, respectively, similar to previous reports. Controversially, Ko et $\mathrm{al}^{10}$ showed that the 5 -year OS, DFS and DMFS were $64.5 \%, 46.2 \%$ and $60 \%$ in $60 \mathrm{ACCHN}$ patients treated by surgery, with or without adjuvant radiation therapy. However, nearly half the patients in this study received either surgery alone or radiotherapy alone. This may be the reason for the lower OS rate. In our study, results showed that distant metastasis is the main failure manner of ACCHN treatment, the most common metastatic site is lung, and among these patients with lung metastases, none oligometastasis was observed, which is consistent with an international cooperation study. ${ }^{2}$

Surgery plays a crucial role in the treatment of ACCHN. Due to the high invasiveness, especially the neural invasion characteristic of the tumor, the R0 resection is difficult to be reached. Postoperative radiotherapy was an effective complementary treatment for locally advanced ACCHN with a residual microscopic tumor. Our data showed that $\mathrm{T}$ stage and clinical stage were independent prognostic factors associated with OS. Previous studies ${ }^{11-14}$ have shown that the larger size of tumors and higher $\mathrm{T}$ stage were associated with poor prognosis. In univariate analysis of this study, patients with a higher $\mathrm{T}$ stage significantly associated with worse OS. Multivariate analysis showed that $\mathrm{T}$ staging remain significance for prognosis, comparable with the results in Choi et al study. ${ }^{15}$ 

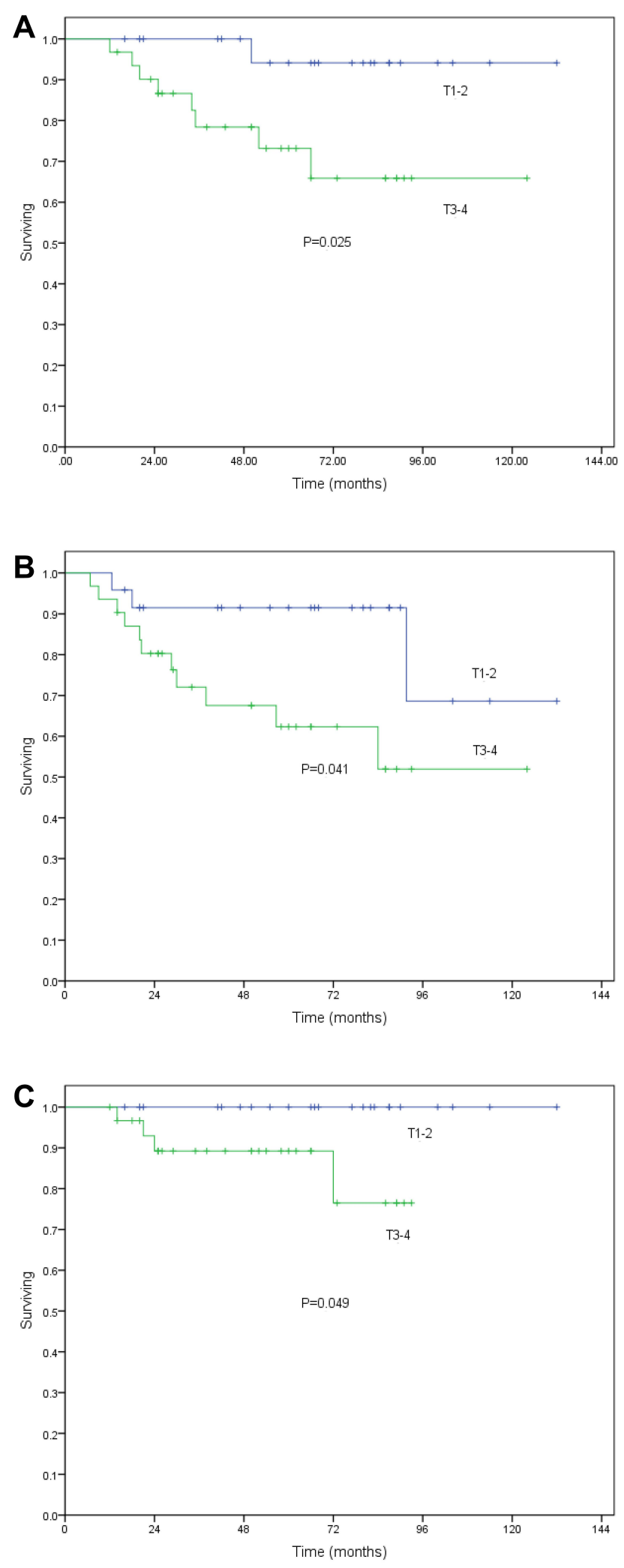

Figure 2 Five-year overall survival (A), distant disease-free survival (B), and localregional recurrence-free survival $(\mathbf{C})$ by the Kaplan-Meier method in all patients by $\mathrm{T}$ stage.
It has been reported that the primary site is an important factor for local recurrence of ACCHN, nasal sinuses, nasal cavity and submandibular glands were suggested to have higher risk to relapse, ${ }^{15,16}$ controversially, the prognosis of large salivary glands and small salivary glands has no statistical difference. ${ }^{17,18}$ In our study, 30 cases $(54.5 \%)$ were located in the large salivary gland and 25 cases $(45.5 \%)$ in the small salivary gland. The LRRFS did not show significant difference between tumor located in the large salivary gland and the small salivary gland. In recent years, clinical studies have shown that postoperative radiotherapy may improve the clinical outcomes of ACCHN patients. A retrospective study ${ }^{15}$ showed that postoperative radiotherapy ( $>59 \mathrm{~Gy})$ significantly improved local control $(p=0.025)$ and DFS $(p=0.001)$. Based on a study in a cohort of 198 patients treated by surgery and postoperative radiotherapy, Garden et $\mathrm{al}^{19}$ suggested that for patients received a R1 resection, the postoperative radiotherapy dose should be at least $60 \mathrm{~Gy}$, while for patients received a $\mathrm{R} 2$ resection, the dose should be 66 Gy. In present study, multivariate statistical analysis showed that radiotherapy dose ( $>60$ Gy) was one of the independent factors for better prognosis. Combine evidence above, we suggested for patients have a residual tumor after operation, treated by IMRT with a higher dose ( $>60 \mathrm{~Gy}$ ) may improve the prognosis.

At present, there is no effective method for the prevention and treatment of distant metastasis of ACCHN, and there is no accepted standard chemotherapy regimen. Many studies have shown low response rate of chemotherapy. ${ }^{18,20,21}$ Platinum, doxorubicin and cyclophosphamide were commonly used. The combined regimen was considered to have high toxicities. Signal drug regimen chemotherapy was suggested to be used for the reason of lower toxicities. ${ }^{22}$ Chemotherapy may be effective only in cases with rapid progression. Similarly, the effect of immunotherapy for ACCHN was not satisfactory, even though some studies found that some ACCHN patients express cancer-testis antigen (CTAs), in which pan-MPGE and NY-ESO-1 were both positive, these patients were expected to improve survival rates through specific immunotherapy. ${ }^{23}$ In our study, half the patients received adjuvant chemotherapy. Chemotherapy drugs were platinum-based combination regimens. The results 
Table 3 Multivariate Analysis for Overall Survival (OS), Distant Disease-Free Survival (DMFS) and Local-Regional Recurrence-Free Survival (LRRFS)

\begin{tabular}{|l|c|c|c|c|c|c|}
\hline & \multicolumn{2}{|c|}{ OS } & \multicolumn{2}{c|}{ DFMS } & \multicolumn{2}{c|}{ LRRFS } \\
\cline { 2 - 7 } & P value & HR (95\% CI) & P value & HR (95\% CI) & P value & HR (95\% CI) \\
\hline T stages 3-4 & 0.026 & 0.088 & 0.053 & 0.272 & 0.991 & 0.087 \\
\hline N stages I-2 & 0.515 & 0.477 & 0.017 & 0.183 & 0.989 & 0.000 \\
\hline AJCC stages III-IVB & 0.028 & 0.089 & 0.040 & 0.193 & 0.976 & 0.001 \\
\hline Small salivary gland & 0.334 & 0.446 & 0.985 & 0.987 & 0.505 & 0.296 \\
\hline RI\&R2 & 0.066 & 0.122 & 0.153 & 0.358 & 0.527 & 2.978 \\
\hline Chemotherapy No & 0.897 & 0.883 & 0.137 & 0.311 & 0.116 & 2.908 \\
\hline RT dose $\geq 60 G$ Gy & 0.025 & 6.628 & 0.241 & 2.231 & 0.65 I & 2.13 . \\
\hline
\end{tabular}

Table 4 Acute and Chronic Adverse Reactions

\begin{tabular}{|l|c|c|c|}
\hline $\begin{array}{l}\text { Chronic Adverse } \\
\text { Reactions }\end{array}$ & $\begin{array}{c}\text { Grade I } \\
\text { (\%) }\end{array}$ & $\begin{array}{c}\text { Grade 2 } \\
\text { (\%) }\end{array}$ & $\begin{array}{c}\text { Grade 3 } \\
\text { (\%) }\end{array}$ \\
\hline Myelosuppression & $9(16.4)$ & $15(27.3)$ & $3(5.5)$ \\
\hline Mucositis & $16(29.1)$ & $22(40.0)$ & $5(9.1)$ \\
\hline Dermatitis & $27(49.1)$ & $11(20.0)$ & $1(1.8)$ \\
\hline Hearing loss & $5(9.1)$ & $3(5.5)$ & $0(0)$ \\
\hline Trismus & $6(10.9)$ & $2(3.6)$ & $1(1.8)$ \\
\hline Xerostomia & $16(29.1)$ & $8(14.5)$ & $1(1.8)$ \\
\hline
\end{tabular}

showed that the addition of adjuvant chemotherapy did not induce a better OS, but improved the control of distant metastasis.

In terms of toxicity, $5.5 \%, 9.1 \%$ and $1.8 \%$ of patients had myelosuppression, mucositis, dermatitis, respectively, and other side effects also observed during the treatment, no late grade 4 toxicity was observed. All toxicities were tolerable, and patients were successfully complete the postoperative adjuvant radiotherapy. Our data suggested IMRT had great advantages in adjuvant radiotherapy for patients with ACCHN.

In conclusion, this study supported the use of postoperative IMRT for local ACCHN patients. Considering the side effects and local control rate, we highly recommend adjuvant IMRT to be used in ACCHN patients.

\section{Funding}

Grant agency of the Science and Technology Department of Sichuan Province (No.20GJHZ0090). These funding supports the present study in the acquisition of data, analysis of data, and manuscript writing.

\section{Disclosure}

The authors declared that they have no conflicts of interest to this work.

\section{References}

1. Coca-Pelaz A, Rodrigo JP, Bradley PJ, et al. Adenoid cystic carcinoma of the head and neck-an update. Oral Oncol. 2015;51:652-661. doi:10.1016/j.oraloncology.2015.04.005

2. Amit M, Binenbaum Y, Sharma K, et al. Analysis of failure in patients with adenoid cystic carcinoma of the head and neck. An international collaborative study. Head Neck. 2014;36(7):998-1004. doi:10.1002/ hed.23405

3. Jang S, Patel PN, Kimple RJ, et al. Clinical outcomes and prognostic factors of adenoid cystic carcinoma of the head and neck. Anticancer Res. 2017;37(6):3045-3052. doi:10.21873/anticanres.11659

4. Li N, Xu L, Zhao H, et al. A comparison of the demographics, clinical features, and survival of patients with adenoid cystic carcinoma of major and minor salivary glands versus less common sites within the surveillance, epidemiology, and end results registry. Cancer. 2012;118 (16):3945-3953. doi:10.1002/cncr.26740

5. Suh Y-G, Lee CG, Kim H, et al. Treatment outcomes of intensity-modulated radiotherapy versus 3D conformal radiotherapy for patients with maxillary sinus cancer in the postoperative setting. Head Neck. 2016;38(Suppl 1):E207-E213. doi:10.1002/hed.23971

6. Tao R, Ma D, Takiar V, et al. Orbital carcinomas treated with adjuvant intensity-modulated radiation therapy. Head Neck. 2016;38(Suppl 1): E580-E587. doi:10.1002/hed.24044

7. Gay HA, Dyk P, Deasy JO, et al. Common Terminology Criteria for Adverse Events (CTCAE) v4.0 based hybrid patient and physician questionnaire for Head and Neck (HN) radiotherapy symptom reporting. Int $J$ Radiat Oncol. 2011;81:S673. doi:10.1016/j. ijrobp.2011.06.929

8. Mendenhall WM, Morris CG, Amdur RJ, et al. Radiotherapy alone or combined with surgery for adenoid cystic carcinoma of the head and neck. Head Neck. 2004;26(2):154-162. doi:10.1002/hed.10380

9. Takebayashi S, Shinohara S, Tamaki H, et al. Adenoid cystic carcinoma of the head and neck: a retrospective multicenter study. Acta Otolaryngol. 2018;138:73-79. doi:10.1080/00016489.2017.1371329 
10. Ko JJ, Siever JE, Hao D, et al. Adenoid cystic carcinoma of head and neck: clinical predictors of outcome from a Canadian centre. Curr Oncol Tor Ont. 2016;23:26-33. doi:10.3747/co.23.2898

11. Khan AJ, DiGiovanna MP, Ross DA, et al. Adenoid cystic carcinoma: a retrospective clinical review. Int J Cancer. 2001;96:149-158. doi:10.1002/ijc.1013

12. Oplatek A, Ozer E, Agrawal A, et al. Patterns of recurrence and survival of head and neck adenoid cystic carcinoma after definitive resection. Laryngoscope. 2010;120(1):65-70. doi:10.1002/lary.20684

13. Zhang Q, Yang L, Yang A, et al. Clinical study on 88 cases of adenoid cystic carcinoma in nasal cavity and paranasal sinuses. Zhonghua Er Bi Yan Hou Tou Jing Wai Ke Za Zhi. 2009;44(4):311-314.

14. van Weert S, Bloemena E, van der Waal I, et al. Adenoid cystic carcinoma of the head and neck: a single-center analysis of 105 consecutive cases over a 30-year period. Oral Oncol. 2013;49 (8):824-829. doi:10.1016/j.oraloncology.2013.05.004

15. Choi Y, Kim S-B, Yoon DH, et al. Clinical characteristics and prognostic factors of adenoid cystic carcinoma of the head and neck. Laryngoscope. 2013;123(6):1430-1438. doi:10.1002/lary.23976

16. Marcinow A, Ozer E, Teknos T, et al. Clinicopathologic predictors of recurrence and overall survival in adenoid cystic carcinoma of the head and neck: a single institutional experience at a tertiary care center. Head Neck. 2014;36(12):1705-1711. doi:10.1002/hed.23523

17. Bjørndal K, Krogdahl A, Therkildsen MH, et al. Salivary adenoid cystic carcinoma in Denmark 1990-2005: outcome and independent prognostic factors including the benefit of radiotherapy. Results of the Danish Head and Neck Cancer Group (DAHANCA). Oral Oncol. 2015;51(12):1138-1142. doi:10.1016/j.oraloncology.2015.10.002
18. Meyers M, Granger B, Herman P, et al. Head and neck adenoid cystic carcinoma: a prospective multicenter REFCOR study of 95 cases. Eur Ann Otorhinolaryngol Head Neck Dis. 2016;133:13-17. doi:10.1016/j.anorl.2015.09.009

19. Garden AS, Weber RS, Morrison WH, et al. The influence of positive margins and nerve invasion in adenoid cystic carcinoma of the head and neck treated with surgery and radiation. Int $J$ Radiat Oncol Biol Phys. 1995;32(3):619-626. doi:10.1016/0360-3016(95)00122-F

20. Dillon PM, Chakraborty S, Moskaluk CA, et al. Adenoid cystic carcinoma: a review of recent advances, molecular targets, and clinical trials. Head Neck. 2016;38(4):620-627. doi:10.1002/hed.23925

21. Subramaniam T, Lennon P, O’Neill JP. Ongoing challenges in the treatment of adenoid cystic carcinoma of the head and neck. Ir J Med Sci. 2015;184(3):583-590. doi:10.1007/s11845-015-1298-1

22. Papaspyrou G, Hoch S, Rinaldo A, et al. Chemotherapy and targeted therapy in adenoid cystic carcinoma of the head and neck: a review. Head Neck. 2011;33:905-911. doi:10.1002/hed.21458

23. Veit JA, Heine D, Thierauf J, et al. Expression and clinical significance of MAGE and NY-ESO-1 cancer-testis antigens in adenoid cystic carcinoma of the head and neck. Head Neck. 2016;38:1008-1016. doi:10.1002/hed.24403

\section{Publish your work in this journal}

Cancer Management and Research is an international, peer-reviewed open access journal focusing on cancer research and the optimal use of preventative and integrated treatment interventions to achieve improved outcomes, enhanced survival and quality of life for the cancer patient.
The manuscript management system is completely online and includes a very quick and fair peer-review system, which is all easy to use. Visit http://www.dovepress.com/testimonials.php to read real quotes from published authors. 